\title{
HLA-DRB1 genes and patients with late onset rheumatoid arthritis
}

\author{
J-P Hellier, J-F Eliaou, J-P Daurès, J Sany, B Combe
}

\begin{abstract}
Objective-To determine the influence of HLA-DRB ${ }^{*} 1$ genes on susceptibility to and severity of rheumatoid arthritis (RA) in patients with late onset compared with younger onset disease.

Methods-The clinical, biological, and HLA-DRB1 typing characteristics of two groups of patients were studied retrospectively. Group 1 consisted of 262 patients whose disease onset was before or at the age of 60 (young onset RA (YORA)). Group 2 included 60 patients whose illness began after the age of 60 (elderly onset RA (EORA)).
\end{abstract}

Results-The shared epitope level was similarly increased in both groups of patients compared with normal controls $(195 / 262(74 \%)$ in group 1 and $43 / 60(72 \%)$ in group $2 v 645 / 1609(40.1 \%)$ in controls). No differences were noted between the two groups of patients for each separate disease related allele. In contrast, when studying all HLA-DRB1*04 RA related alleles as a group, these alleles were underrepresented in EORA compared with YORA $(22 / 60(37 \%) v 135 / 262(52 \%)$; odds ratio $2.0 ; 95 \%$ confidence interval 1.0 to 3.3). An inverse trend was seen for HLA-DRB $1{ }^{\star} 01$ alleles. There were no differences in biological characteristics or extra-articular manifestations between the patient groups. The differences noted in radiological evaluation or the number of prescribed disease modifying antirheumatic drugs seemed to be linked with differences in disease duration.

Conclusion-HLA-DRB1 RA related alleles influence both EORA and YORA. However, HLA-DRB1 *04 RA linked alleles are not as closely associated with RA in the elderly as they are in younger patients. This suggests that the importance of these genes in the susceptibility to RA may be lower in elderly patients.

(Ann Rheum Dis 2001;60:531-533)

Rheumatoid arthritis (RA) is one of the most common autoimmune diseases. Its incidence peaks at age 35-55 and many patients develop their first manifestation of RA before the age of 60 . However, with the increasing proportion of elderly people in the general population, late onset RA is likely to become an increasing health problem. Many studies have assessed patterns of joint and systemic involvement, as well as the clinical course in elderly onset RA (EORA), but opinions still differ as to whether the variations in RA characteristics found give rise to differences in prognosis compared with younger patients. ${ }^{1-3}$

Many publications have focused on the influence of the genetic background on the clinical presentation of RA. Some HLA-DR genes seem to be particularly important for both the susceptibility to and severity of RA (HLA-DRB1*0101, 0102, 0401, 0404, 0405, 0408, 1001, 1402). All these alleles share a sequence motif in the third hypervariable region of the HLA-DRB1 gene, the so-called "shared epitope". Only a few authors have compared potential differences between the immunogenetic background of young onset RA (YORA) with those of EORA..$^{3-7}$

We studied the clinical features, genetic background, treatment, and outcome in a group of patients with EORA and compared these findings with those in a group of patients with RA whose illness began at a younger age.

\section{Material and methods \\ PATIENTS}

Three hundred and twenty two consecutive patients from a population in southern France who fulfilled the 1987 American College of Rheumatology criteria for RA were selected for this study and followed up at our institution. They all had radiological and immunogenetic assessment.

Two groups of French white patients were selected based on their age at disease onset. In group $1(n=262)$ the disease had begun before the age of 60 (YORA) and in group $2(n=60)$ after the age of 60 (EORA). The medical records of these patients were reviewed retrospectively. The age at disease onset was defined as the age of the first joint swelling. The control group consisted of 1609 healthy blood donors.

CLINICAL, BIOLOGICAL, AND RADIOLOGICAL

ASSESSMENTS

Clinical assessment focused on the presence of extra-articular manifestations, history of joint surgery, and drug treatment regimens.

A the time of the study, rheumatoid factor (RF) status was assessed by laser nephelometry. The presence of antinuclear antibodies (ANA) was demonstrated by an indirect fluorescent antibody technique. Radiographs of the hands, wrists, and feet were assessed by one observer (JPH), using Larsen's method.

IMMUNOGENETIC ANALYSIS

Genomic DNA was isolated from peripheral blood mononuclear cells. HLA-DRB1* genotyping was performed on genomic DNA after polymerase reaction amplification with groupspecific primers using specific oligonucleotides 
Table 1 Patient characteristics

\begin{tabular}{llll}
\hline & $\begin{array}{l}\text { YORA } \\
(n=262)\end{array}$ & $\begin{array}{l}\text { EOR } A^{\star} \\
(n=60)\end{array}$ & $p$ Value \\
\hline Mean (SD) age (years) & $53.7(53.6)$ & $72.4(5.4)$ & \\
Mean (SD) age at onset & $42.5(11.5)$ & $66.9(5.4)$ & $<0.00001$ \\
Women (\%) & $207(79)$ & $36(60)$ & $<0.01$ \\
Disease duration (SD) & $11.4(8.9)$ & $5.7(4.6)$ & $<0.0001$ \\
Nodules (\%) & $61(23)$ & $11(18)$ & 0.25 \\
Raynaud's disease (\%) & $40(15)$ & $8(13)$ & 0.85 \\
Sicca syndrome (\%) & $79(30)$ & $18(30)$ & 0.85 \\
EAM ${ }^{\star}(\%)$ & $22(8)$ & $5(8)$ & 1 \\
RF $^{\star}$ positive (\%) $\dagger$ & $158(60)$ & $32(53)$ & 0.064 \\
Mean (SD) RF titre (IU/ml) $^{\star}$ & $413(629)$ & $461(560)$ & 0.9 \\
ANA positive (\%) & $54(21)$ & $14(23)$ & 1 \\
\hline
\end{tabular}

^YORA = young onset RA; EORA = elderly onset RA; EAM = extra-articular manifestations; $\mathrm{RF}=$ rheumatoid factor; $\mathrm{ANA}=$ antinuclear antibodies.

$\dagger>20 \mathrm{IU} / \mathrm{ml}$.

as previously described. ${ }^{8}$ Subtyping for $\mathrm{DRB} 1{ }^{\star} 04$ and $\mathrm{DRB} 1{ }^{\star} 01$ alleles was carried out by the polymerase chain reaction with sequence-specific primers method. ${ }^{9}$

STATISTICS

Statistical analysis was performed using BMDP statistical software. ${ }^{10}$ Fisher's exact test or the $\chi^{2}$ test and the non-parametric KruskalWallis test or one way analysis of variance was used for between-group comparisons of qualitative and quantitative data, respectively. Odds ratios with $95 \%$ confidence interval were estimated by the Mantel-Haenszel method.

\section{Results}

DEMOGRAPHIC CHARACTERISTICS:

Table 1 gives the patients' characteristics. The EORA group had significantly more male patients, tended to be less rheumatoid factor (RF) positive, and had significantly shorter disease duration than patients with YORA. No difference was found for the other clinical and biological variables.

HLA-DRB1 GENOTYPING

HLA-DRB1 oligotyping disclosed an expected increased presence of the shared epitope in both groups of patients as compared with normal controls (table 2). A DRB $1^{\star} 04$ or $\mathrm{DRB} 1{ }^{\star} 01 \mathrm{RA}$ associated allele was found in $195 / 260(74 \%)$ patients in group 1 compared with $43 / 60(72 \%)$ in group 2 . One hundred and thirty nine patients in group $1(53 \%)$ and 36 in group $2(60 \%)$ carried a single allele. Fifty six patients of group $1(21 \%)$ and seven patients of group $2(12 \%)$ carried two disease related alleles. None of these differences was significant (table 2). No differences in HLADRB1 typing between male and female patients were found.

Table 2 Shared epitope frequencies in patients with young onset $R A(Y O R A)$, elderly onset $R A$ (EORA), and in controls

\begin{tabular}{|c|c|c|c|c|c|}
\hline & \multicolumn{2}{|c|}{ YORA $(n=262)$} & \multicolumn{2}{|c|}{$E O R A(n=60)$} & \multirow{2}{*}{$\begin{array}{l}\text { Controls } \\
(n=1609) \\
\text { No } \%\end{array}$} \\
\hline & No (\%) & $O R^{\star}(95 \% C I)$ & No(\%) & $O R^{\star}(95 \% C I)$ & \\
\hline $\mathrm{SE}^{\star}$ homozygotes & $17(6)$ & $13.9(5.9$ to 32.5$)$ & $2(3) \dagger$ & $6.9(1.4$ to 33.2$)$ & $8(0.5)$ \\
\hline SE heterozygotes & $39(15)$ & $4.4(2.9$ to 6.8$)$ & $5(8) \dagger$ & $2.3(0.9$ to 5.9$)$ & $61(3.8)$ \\
\hline $\mathrm{SE} / \mathrm{DRx}$ & $139(53)$ & $2.0(1.5$ to 2.6$)$ & $36(60) \dagger$ & $2.7(1.5$ to 4.5$)$ & $576(35.8)$ \\
\hline $\mathrm{DRx} / \mathrm{DRx} \neq$ & $67(26)$ & $0.2(0.1$ to 0.3$)$ & $17(28) \dagger$ & $0.3(0.1$ to 0.5$)$ & $964(59.9)$ \\
\hline
\end{tabular}

${ }^{\star} \mathrm{OR}(95 \% \mathrm{CI})=$ odds ratio $(95 \%$ confidence interval $)$ versus controls; $\mathrm{SE}=$ shared epitope. tEORA versus YORA: NS.

$\ddagger \mathrm{DRx}=$ any DR gene but RA associated alleles.
Table 3 Frequency of HLA-DRB1 ${ }^{\star} 04 R A$ linked alleles (0401,0404,0405,0408) and DRB1*01 RA linked alleles $(0101,0102)$ in young onset rheumatoid arthritis (YORA) and elderly onset rheumatoid arthritis (EORA) subsets. Results are shown as No (\%)

\begin{tabular}{lrll}
\hline & $\begin{array}{l}\text { YORA } \\
(n=262)\end{array}$ & $\begin{array}{l}\text { EORA } \\
(n=60)\end{array}$ & $\begin{array}{l}\text { Odd ratio } \\
(95 \% \mathrm{CI})\end{array}$ \\
\hline $\mathrm{DRB}^{\star}{ }^{\star} 04$ & $135(52)$ & $22(37)$ & $2.0(1.0$ to 3.3$)$ \\
$\mathrm{DRB} 1^{\star} 01$ & $78(30)$ & $22(37)$ & $0.7(0.4$ to 1.3$)$ \\
$\mathrm{DRB} 1^{\star} 01$ or 04 & $195(74)$ & $43(72)$ & $1.1(0.6$ to 2.1$)$ \\
\hline
\end{tabular}

There were no significant differences between the two groups of patients in the distribution of each HLA-DRB1 genotype (data not shown). However, when studying all HLA-DRB ${ }^{\star} 04$ RA associated alleles (0401, 0404, 0405, 0408), HLA-DRB1 ${ }^{\star} 04$ was more frequently present in the patients with YORA $(135 / 262(52 \%))$ than in the patients with EORA (22/60 (37\%); p=0.045) (table 3). An inverse trend was found for HLA-DRB1 ${ }^{\star} 0101$ genes that are associated with RA (78/262 $(30 \%)$ v $22 / 60(37 \%))$, but the difference between the groups was not statistically significant.

RADIOLOGICAL SCORES

Larsen scores were significantly higher in patients with YORA than in those with EORA: 53.3 (42.1) $v 36.2(30.1)$ for hand $x$ rays $(\mathrm{p}=0.003)$ and $19.9(18.5) \cup 12.5$ (13.2) for foot radiographs $(p=0.0067)$. However, no difference in radiological severity was found between the two groups of patients after adjustment for disease duration $(p=0.23)$. An association was found between radiological severity and HLA-DRB $1^{\star} 04$ alleles $(p=0.03)$.

NUMBER OF PRESCRIBED DISEASE MODIFYING ANTIRHEUMATIC DRUGS

Patients with EORA received significantly more second line agents and required surgery more often for joint destruction. However, these differences were eliminated after adjustment for disease duration (data not shown). No relation was found between the therapeutic regimen and genetic typing.

\section{Discussion}

Differences between elderly and earlier onset of disease have frequently been described, but there is no consensus on the importance of this observation. ${ }^{1-3}$ This study focused on genetic markers that could distinguish between patients according to their age at onset of RA.

Clinical characteristics were the same in both groups of patients except for the percentage of women $-79 \%$ in patients with YORA and $60 \%$ in the EORA group $(\mathrm{p}<0.01)$. Published results on the sex ratio according to age at disease onset vary. Some authors report an increase in the proportion of men in the group with EORA, ${ }^{11} 12$ whereas others failed to show any variation, or they found an increase in the percentage of women in the EORA groups. ${ }^{25} 13$

No significant difference was found in the presence of rheumatoid nodules or extraarticular manifestations, or RF positivity between our two groups of patients, as reported. $^{151314}$ The retrospective design of this 
study did not allow an acute evaluation of potential differences in radiological damage between our patients. When adjusted for disease duration, the radiological severity seemed to be similar in both groups. Similarly, no differences were found in a recent prospective study with a median radiological follow up of 3.6 years. $^{3}$

In our group, HLA-DRB1 genotyping showed an increase in the frequency of the shared epitope in both groups of patients compared with healthy controls. Only a few studies have investigated the HLA features of elderly onset RA. ${ }^{3-8}$ Furthermore, HLA-DRB1 ${ }^{\star}$ genotyping was performed in only one of these previous studies. ${ }^{6}$ The influence of genetic factors in a group with EORA has already been shown by other authors, who found an increase in the frequency of risk alleles in their patients compared with a healthy control group. ${ }^{36}$ The presence of the shared epitope appears to be similar in both EORA and YORA groups of patients. $^{36}$

A study of the frequency of each disease related allele did not show any differences between our two groups of patients, but the presence of HLA-DRB $1^{\star} 04$ RA linked alleles was less common in patients with EORA than in patients with YORA (37\% v 52\%). An inverse trend was found for $\mathrm{DRB} 1{ }^{\star} 01$ alleles, but the difference was not significant. There seemed to be phenotypic differences in our groups according to the age at disease onset. This difference was not detected by van der Heijde et al or Pease et al when they compared HLA-DR4 typing of two groups of patients according to their age at disease onset, ${ }^{35}$ but these studies were performed with serological typing and did not permit definite conclusions because of the possible confusion between risk and non-risk alleles. Despite the fact that a Japanese population has a different background and HLA association, Yukioka et al using HLA-DRB1 genotyping showed differences in some RA linked alleles (DRB $1^{\star} 0101$, 0405, 1502) between their two groups of patients. ${ }^{6}$ More recently, Bulpitt et al found that DR4 allele frequencies declined with increasing age of RA onset. ${ }^{7}$ They noticed that by age 60 , the allele frequency was comparable with that reported for seronegative RA.

Our data, together with the results of these two recent studies, suggest that HLADRB1*04 RA linked alleles are less strongly associated with RA in elderly than in young patients, and that the importance of these genes in susceptibility to the disease may be lower in elderly patients.

As HLA-DRB $1{ }^{\star} 04$ genes are usually linked to more severe $\mathrm{RA},{ }^{10}{ }^{15}$ our data also suggest that RA may be more benign in elderly patients, as already proposed. ${ }^{2}$ We failed to confirm this clinical outcome and this point should be re-evaluated in a prospective study.

1 Ferraccioli GF, Cavalieri F, Mercadanti M, Conti G, Viviano P, Ambanelli U. Clinical features, scintiscan characteristics and X-ray progression of late onset rheumatoid arthritis. Clin Exp Rheumatol 1984;2:157-61.

2 Deal CL, Meenan RF, Goldenberg DL, Anderson JJ, Sack B, Pastan RS, et al. The clinical features of elderly-onset rheumatoid arthritis. Arthritis Rheum 1985;28:987-94.

3 Pease CT, Bhakta BB, Devlin J, Emery P. Does the age of onset of rheumatoid arthritis influence phenotype? A prospective study of outcome and prognostic factors. Rheumatology 1999;38:228-34.

4 Terkeltaub R, Decary F, Esdaile J. An immunogenetic study of older age onset rheumatoid arthritis. J Rheumatol 1984; 11:147-52.

5 van der Heijde DMFM, van Riel PLCM, van Leeuwen MA, van't Hof MA, van Rijswijk MH, van de Putte LBA. Older versus younger onset rheumatoid arthritis: results at onset and after 2 years of a followup study of early RA. J Rheumatol 1991;18:1285-9.

6 Yukioka M, Wakitani S, Murata N, Toda Y, Ogawa R, Kaneshige $\mathrm{T}$, et al. Elderly-onset rheumatoid arthritis and its association with HLA-DRB1 alleles in Japanese. Br J Rheumatol 1998;37:98-101.

7 Bulpitt KJ, Nepom G, Park G, Sterz MG, Abedi B, Wong WK, et al. Presence of HLA DRB1 susceptibility alleles is associated with earlier onset of seropositive RA: results from an early RA cohort [abstract]. Arthritis Rheum 1999; 42(suppl):S126.

8 Eliaou JF, Palmade F, Avinens O, Edouard E, Ballaguer P, Nicolas JC, et al. Generic HLA-DRB1 oligotyping by a non radioactive reverse dot-blot methodology. Hum Immunol 1992;35:215-22.

9 Olerup O, Zetterquist H. HLA-DR typing by PCR amplification with sequence specific primers (PCR-SSP) in 2 hours: an alternative to serological DR typing in clinical practice including donor-recipient matching in cadaveric transplantation. Tissue Antigens 1992;39:225-35.

10 Combe B, Eliaou JF, Daures JP, Meyer O, Clot J, Sany J. Prognostic factors in rheumatoid arthritis. Comparative study of two subsets of patients according to severity of articular damage. Br J Rheumatol 1995;34:529-34.

11 Alarcon GS. Epidemiology of rheumatoid arthritis. Rheum Dis Clin North Am 1995;21:589-605.

12 Eberhardt KB, Rydgren LC, Pettersson H, Wollheim FA. Early rheumatoid arthritis. Onset, course, and outcome over 2 years. Rheumatol Int 1990;10:135-42.

13 Terkeltaub R, Esdaile J, Decary F, Tannenbaum H. A clinical study of older age rheumatoid arthritis with comparison to a younger onset group. J Rheumatol 1983;10:418-24.

14 Calvo-Alven J, Corrales A, Sanchez Andrada S, Pena JL, Rodriguez Valverde V. Age of onset and outcome in rheumatoid arthritis: a comparative analysis between young and elderly patients [abstract]. Arthritis Rheum 1997;40: (suppl):S152.

15 Weyand CM, McCarthy TG, Goronzy JJ. Correlation between disease phenotype and genetic heterogeneity in rheumatoid arthritis. J Clin Invest 1995;95:2120-6. 